\title{
Determination of copepod grazing on natural plankton communities: correcting for trophic cascade effects
}

\author{
Christine Klaas $^{1, *}$, Peter G. Verity ${ }^{2}$, Sabine Schultes ${ }^{1,3}$ \\ ${ }^{1}$ Alfred Wegener Institute for Polar and Marine Research, Am Handelshafen 12, 27570 Bremerhaven, Germany \\ ${ }^{2}$ Skidaway Institute of Oceanography, 10 Ocean Science Circle, Savannah, Georgia 31411, USA \\ ${ }^{3}$ Present address: LEMAR, Institut Universitaire Européen de la Mer, Place Nicolas Copernic, Technopole Brest Iroise, \\ 29280 Plouzané, France
}

\begin{abstract}
Grazing rates and grazing selectivity of Antarctic copepods (Rhincalanus gigas, Calanus simillimus and copepods 0.8 to $2 \mathrm{~mm}$ in size) were determined using incubation experiments comparing plankton community development with and without added grazers. Estimates of grazing rates were corrected for trophic cascade effects using a simple ecosystem model composed of 5 compartments: (1) nanophytoplankton, (2) nanozooplankton, (3) microphytoplankton, (4) microzooplankton (mainly protozoans) and (5) copepods. Copepod grazing rates on the different planktonic compartments were derived by solving for model parameters as constrained by microscopy enumeration of nano- and microphytoplankton and nano- and microprotozooplankton in treatments with and without added copepods. Simulations based on different parameter values and model configurations support the notion that grazing estimates were robust and between 18 and $30 \%$ higher than uncorrected estimates. Furthermore, model analyses suggest the presence of an additional trophic cascade effect due to grazing of $R$. gigas on small copepods and copepod developmental stages present in incubation bottles.
\end{abstract}

KEY WORDS: Ecosystem model $\cdot$ Zooplankton $\cdot$ Copepod grazing $\cdot$ Southern Ocean $\cdot$ Rhincalanus gigas $\cdot$ Calanus simillimus

\section{INTRODUCTION}

Estimating grazing rates of metazooplankton is key to understanding plankton dynamics in the ocean. Several methods exist to estimate the effect of in situ metazooplankton grazing on natural plankton communities. The most common are measurements of respiration rates $\left(\mathrm{O}_{2}\right.$ changes in closed bottles), the gut fluorescence method, and comparisons of incubations using natural communities with and without added metazooplankton. When used simultaneously, these different methods are known to yield widely differing results (Peterson et al. 1990, Atkinson 1994, 1996, Zeldis 2001). Differences in results for different methods can be attributed to poorly constrained parameters (i.e. pigment destruction in guts, Conover et al. 1986, Head \& Harris 1992), manipulation of the metazooplankton during capture causing disturbances in feeding behaviour (all methods) and changes in physiology and behaviour due to incubation conditions (i.e. gut fluorescence and $\mathrm{O}_{2}$ measurements are done in filtered seawater; Ikeda 1977, Roman \& Rublee 1980, Baars \& Helling 1985, Ikeda et al. 2000). Comparison of incubations with and without metazooplankton has several advantages. If the volume of incubation is large and incubation time is long enough, disturbances due to manipulation might be minimized. Moreover, grazing estimates are not limited to phytoplankton, and information on feeding rates as well as selectivity can be obtained from microscopy. A possible problem with 
this method, however, is the occurrence of trophiccascade effects that complicate interpretation of results. Nejstgaard et al. $(1997,2001)$ proposed a correction for trophic cascade effects based on dilution experiments (Landry \& Hassett 1982) to determine the growth rates of phytoplankton and grazing rates of microzooplankton. This combination of methods, apart from being laborious, generates a large number of samples to be counted, should detailed information on feeding selectivity be required. We propose a correction for trophic cascade effects based on a simple ecosystem model that can be applied to the comparison of incubations using natural communities with and without added copepods. This method was applied to incubation experiments of natural communities carried out during an iron fertilization experiment (EisenEx, Smetacek et al. 2001, Schultes et al. 2006).

\section{MATERIALS AND METHODS}

Experimental conditions. Seven incubation experiments were carried out to determine the grazing response and selectivity of 2 copepod species (adult females of Rhincalanus gigas and Calanus simillimus) and unidentified mixtures of small copepods (0.8 to $2 \mathrm{~mm}$ in size) to changes in phytoplankton standing stocks and composition. The experiments were carried out during an iron fertilization experiment in the Atlantic sector of the Southern Ocean Polar Front region (Gervais et al. 2002, Cisewsky et al. 2005, Schultes et al. 2006, Henjes et al. 2007). Experimental conditions are given in Table 1 and described in detail by Schultes et al. (2006). Briefly, water samples containing natural plankton communities were collected using Niskin bottles mounted on a CTD rosette during cruise ANT XVIII/2 (EisenEx) of RV 'Polarstern'. Water samples were transferred into five 11 plastic bottles (3 replicate bottles for the copepod treatments and duplicate bottles for the control treatments). Copepods were collected using vertical bongo net hauls $(300 \mu \mathrm{m}$ mesh size) in the upper 200 to $350 \mathrm{~m}$ of the water column. Once on deck, the net catch was gently diluted into $10 \mathrm{l}$ of seawater. Actively swimming copepods were chosen and transferred into the incubation bottles for the copepod treatments. Bottles were placed on a plankton wheel in the dark at $4^{\circ} \mathrm{C}$. Sub-samples of the bongo net hauls were collected on a fine mesh, immediately frozen at $-80^{\circ} \mathrm{C}$ and stored at $-20^{\circ} \mathrm{C}$ for later determination of copepod carbon content. On land, samples were thawed, re-suspended in $0.2 \mu \mathrm{m}$ filtered seawater and dominant copepods in the catch sorted in a Petri dish under a stereomicroscope. Copepods were rapidly washed twice in de-ionized water and 1 to 15 individuals of the same size or stage were transferred to a cleaned (acetone, chloroform) and pre-weighed tin cup. The cups with the copepods were weighed, dried for $24 \mathrm{~h}$ at 50 to $60^{\circ} \mathrm{C}$ and weighed again to determine wet and dry weights. Samples were then analyzed for carbon and nitrogen content with a Carlo-Erba elemental analyzer (Schultes 2004).

Samples for cell counts were taken at the beginning, and after 1 or $2 \mathrm{~d}$ of incubation (Table 1). Diatom counts were made using the method of Utermöhl (1958) on subsamples preserved with acidic Lugol's iodine. Samples for the analysis of ciliates and heterotrophic dinoflagellates were preserved with $0.3 \%$ glutaraldehyde, stained with Proflavin and DAPI, filtered onto $0.8 \mu \mathrm{m}$ black Nuclepore filters and mounted on a slide with a drop of low fluorescence immersion oil and a cover slip. Slides were stored at $-20^{\circ} \mathrm{C}$ until ana-

Table 1. Incubation experiments and experimental conditions. Expt: experiment number (same as in Schultes et al. 2006). Stn: station number. Treatment: type of copepods added in the copepod treatments. N: number of copepods added in treaments.

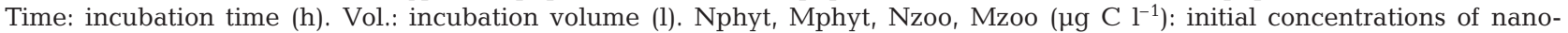
phytoplankton, microphytoplankton, nanozooplankton, microzooplankton, respectively, in incubation bottles. $\Delta \mathrm{Np}, \Delta \mathrm{Mp}, \Delta \mathrm{Nz}$, $\mathrm{Mz}\left(\mu \mathrm{g} \mathrm{C}^{-1}\right)$ : differences in concentrations of nanophytoplankton, microphytoplankton, nanozooplankton and microzooplankton, respectively, between control incubations and treatment with added copepods at the end of the experiments. $C$. simillimus: Calanus simillimus. $R$. gigas: Rhincalanus gigas

\begin{tabular}{|c|c|c|c|c|c|c|c|c|c|c|c|c|c|c|}
\hline Expt & Date & Stn & Treatment & $\mathrm{N}$ & Time & Vol. & Nphyt & $\Delta \mathrm{Np}$ & Mphyt & $\Delta \mathrm{Mp}$ & Nzoo & $\Delta \mathrm{Nz}$ & Mzoo & $\Delta \mathrm{Mz}$ \\
\hline $1 \mathrm{a}$ & 7.11 .2000 & $9^{a}$ & Small copepods & 10 & 24 & 1.19 & 8.71 & -0.14 & 4.37 & 0.50 & 5.18 & -0.31 & 2.66 & -0.35 \\
\hline 4 & 15.11 .2000 & $45^{\mathrm{a}}$ & Small copepods & 20 & 41 & 1.19 & 7.81 & -0.07 & 9.16 & -0.16 & 8.13 & -0.44 & 6.48 & -2.19 \\
\hline $7 a$ & 25.11 .2000 & 89,90 & Small copepods & 15 & 34 & 1.19 & 10.94 & -0.5 & 7.58 & -1.23 & 7.15 & -0.12 & 4.85 & -1.56 \\
\hline 2 & 10.11 .2000 & $14^{\mathrm{a}}$ & C. simillimus & 5 & 28 & 1.19 & 10.36 & 0.17 & 4.63 & -4.93 & 6.68 & 0.13 & 3.93 & -2.54 \\
\hline 5 & 16.11 .2000 & $46^{\mathrm{a}}$ & C. simillimus & 5 & 36 & 1.19 & 8.41 & 0.75 & 9.43 & -7.99 & 9.50 & 0.03 & 7.60 & -4.25 \\
\hline $7 b$ & 25.11 .2000 & 89,90 & C. simillimus & 5 & 34 & 1.19 & 10.94 & 1.68 & 7.58 & -4.24 & 7.15 & 1.56 & 4.85 & -0.37 \\
\hline $1 b$ & 7.11 .2000 & $9^{\mathrm{a}}$ & $R$. gigas & 5 & 24 & 1.19 & 8.71 & 1.78 & 4.37 & 0.22 & 5.18 & 1.85 & 2.66 & -1.66 \\
\hline 3 & 13.11 .2000 & 42 & $R$. gigas & 4 & 43 & 1.19 & 9.57 & 2.59 & 5.31 & 0.03 & 7.08 & 1.05 & 3.18 & -3.17 \\
\hline 6 & 24.11 .2000 & $88^{\mathrm{a}}$ & R. gigas & 4 & 30 & 1.19 & 14.72 & 2.10 & 11.75 & -5.40 & 13.96 & 2.12 & 12.10 & -5.88 \\
\hline
\end{tabular}


lysis. Ciliates and heterotrophic dinoflagellates were counted using an epifluorescence microscope to distinguish autotrophs from heterotrophs. Mixotrophic dinoflagellates were considered as autotrophs and not included in the heterotrophic dinoflagellate counts, whereas all ciliates were considered as heterotrophs. Average variability of count data estimated from the triplicate copepod treatments in each experiment was $3 \%$ for the nanophytoplankton, $18 \%$ for the microphytoplankton (diatoms), $3 \%$ for the nanozooplankton and $2 \%$ for the microzooplankton. The corresponding variability of carbon standing stocks was $3 \%$ for the nanophytoplankton, $24 \%$ for the microphytoplankton (diatoms), $3 \%$ for the nanozooplankton and $4 \%$ for the microzooplankton. The high variability of microphytoplankton biomass can be attributed to large diatoms that contributed significantly to biomass but tended to be present in low numbers. Auto- and mixotrophic microflagellates (including dinoflagellates) were not counted in these experiments.

Uncorrected estimation of grazing rates in the incubation bottles. Grazing estimates that did not account for trophic cascade effects were calculated assuming constant growth and grazing mortality rates:

$$
\begin{gathered}
\mathrm{d} P_{\mathrm{c}} / \mathrm{d} t=\mu P_{\mathrm{c}} \\
\mathrm{d} P_{\mathrm{z}} / \mathrm{d} t=(\mu-g) P_{\mathrm{z}}
\end{gathered}
$$

where $\mu$ is specific growth rates of prey $\left(\mathrm{h}^{-1}\right), g$ is specific mortality rates of prey $\left(\mathrm{h}^{-1}\right), P_{\mathrm{c}}$ is prey standing stocks in control incubation bottles $(\mu \mathrm{g} \mathrm{C})$, and $P_{\mathrm{z}}$ is prey standing stock in incubation bottles with added copepods ( $\mu \mathrm{g} \mathrm{C})$.

Using Eqs. (1) \& (2), values for $g$ (Eq. 3) and the amount of phytoplankton grazed by the copepods can be derived:

$$
\begin{gathered}
g=-\ln \left(P_{\mathrm{z}} / P_{\mathrm{c}}\right) / t \\
\mathrm{~d} P_{\mathrm{g}} / \mathrm{d} t=g P_{\mathrm{z}} \\
P_{\mathrm{g}}=g /(\mu-g) P_{0}\left(\mathrm{e}^{(\mu-g) t}-1\right)
\end{gathered}
$$

where $t_{0}=0$ and $t=$ the time at the end of the incubation, respectively. $P_{0}$ is the phytoplankton biomass ( $\mu \mathrm{g}$ C) at the start of the experiment and $P_{\mathrm{g}}$ the phytoplankton biomass ( $\mu \mathrm{g} C$ ) grazed by copepods during the course of the experiments. The amount of phytoplankton biomass grazed per copepod per unit time $(G)$ is therefore:

$$
G=P_{\mathrm{g}} /(n t)
$$

where $n$ is the number of copepods added per incubation bottle.

Corrected estimation of grazing rates in the incubation bottles. The correction of grazing rates was based on an ecosystem model with 5 compartments encompassing 3 size classes: (1) nanophytoplankton and (2) nanozooplankton (protists $<20 \mu \mathrm{m}$ ), (3) microphytoplankton and (4) microzooplankton (protists between 20 and $200 \mu \mathrm{m}$ ), and (5) the mesozooplankton comprising the copepods added to the incubation bottles. Diatoms $>20 \mu \mathrm{m}$ were pooled in the microphytoplankton. All autotrophs $<20 \mu \mathrm{m}$ were assigned to the nanophytoplankton (irrespective of taxonomic affiliation). Nanoheterotrophs were assumed to graze on bacteria and were grazed in turn by microzooplankton and copepods. Ciliates and heterotrophic flagellates $>20 \mu \mathrm{m}$ constituted the microzooplankton. The microzooplankton was assumed to graze on nanoplankton and microphytoplankton without preference. Growth of the different compartments in the control incubations can be represented as follows:

$$
\begin{gathered}
\mathrm{d} P_{\mathrm{n}} / \mathrm{d} t=\mu_{P_{\mathrm{n}}} P_{\mathrm{n}}-g_{\mathrm{m}} P_{\mathrm{n}} Z_{\mathrm{m}} \\
\mathrm{d} P_{\mathrm{m}} / \mathrm{d} t=\mu_{P_{\mathrm{m}}} P_{\mathrm{m}}-g_{\mathrm{m}} P_{\mathrm{m}} Z_{\mathrm{m}} \\
\mathrm{d} Z_{\mathrm{n}} / \mathrm{d} t=\mu_{Z_{\mathrm{n}}} Z_{\mathrm{n}}-g_{\mathrm{m}} Z_{\mathrm{n}} Z_{\mathrm{m}} \\
\mathrm{d} Z_{\mathrm{m}} / \mathrm{d} t=f g_{\mathrm{m}} Z_{\mathrm{m}}\left(P_{\mathrm{n}}+P_{\mathrm{m}}+Z_{\mathrm{n}}\right)
\end{gathered}
$$

where $P_{\mathrm{n}}$ is the nanophytoplankton concentration ( $\mu \mathrm{g}$ C), $P_{\mathrm{m}}$ is the microphytoplankton concentration ( $\left.\mu \mathrm{g} \mathrm{C}\right)$, $Z_{\mathrm{n}}$ is the nanozooplankton concentration ( $\left.\mu \mathrm{g} \mathrm{C}\right), Z_{\mathrm{m}}$ is the microzooplankton concentration $(\mu \mathrm{g} C), \mu_{P_{\mathrm{n}}}$ is the nanophytoplankton growth rate $\left(\mathrm{h}^{-1}\right), \mu_{P_{\mathrm{m}}}$ is the microphytoplankton growth rate $\left(\mathrm{h}^{-1}\right), \mu_{Z_{\mathrm{n}}}$ is the nanozooplankton growth rate $\left(\mathrm{h}^{-1}\right), g_{\mathrm{m}}$ is the microzooplankton grazing rate $\left([\mu \mathrm{g} \mathrm{C}]^{-1} \mathrm{~h}^{-1}\right)$, and $f$ is the conversion efficiency (or gross growth efficiency) for the microzooplankton (dimensionless).

Assuming that the microzooplankton was not grazed in the control treatments and knowing the conversion efficiency $(f)$ of prey into predator biomass for the microzooplankton, the growth rates for phytoplankton and nanoheterotrophs can be derived. In the model representing the dynamics in treatments with added copepods, we assigned different copepod grazing rates to the different compartments:

$$
\begin{gathered}
\mathrm{d} P_{\mathrm{n}} / \mathrm{d} t=\mu_{P_{\mathrm{n}}} P_{\mathrm{n}}-g_{\mathrm{m}} P_{\mathrm{n}} Z_{\mathrm{m}}-g_{\mathrm{za}} P_{\mathrm{n}} Z_{\mathrm{z}} \\
\mathrm{d} P_{\mathrm{m}} / \mathrm{d} t=\mu_{P_{\mathrm{m}}} P_{\mathrm{m}}-g_{\mathrm{m}} P_{\mathrm{m}} Z_{\mathrm{m}}-g_{\mathrm{zb}} P_{\mathrm{m}} Z_{\mathrm{z}} \\
\mathrm{d} Z_{\mathrm{n}} / \mathrm{d} t=\mu_{Z_{\mathrm{n}}} Z_{\mathrm{n}}-g_{\mathrm{m}} Z_{\mathrm{n}} Z_{\mathrm{m}}-g_{\mathrm{zc}} Z_{\mathrm{n}} Z_{\mathrm{z}} \\
\mathrm{d} Z_{\mathrm{m}} / \mathrm{d} t=f g_{\mathrm{m}} Z_{\mathrm{m}}\left(P_{\mathrm{n}}+P_{\mathrm{m}}+Z_{\mathrm{n}}\right)-g_{\mathrm{zd}} Z_{\mathrm{m}} Z_{\mathrm{z}}
\end{gathered}
$$

where $g_{\text {za }}$ is the copepod grazing rate on the nanophytoplankton $\left([\mu \mathrm{g} \mathrm{C}]^{-1} \mathrm{~h}^{-1}\right), g_{\mathrm{zb}}$ is the copepod grazing rate on the microphytoplankton $\left([\mu \mathrm{g} \mathrm{C}]^{-1} \mathrm{~h}^{-1}\right), g_{\mathrm{zc}}$ is the copepod grazing rate on the nanozooplankton $\left([\mu \mathrm{g} \mathrm{C}]^{-1} \mathrm{~h}^{-1}\right), g_{\mathrm{zd}}$ is the copepod grazing rate on the microzooplankton $\left([\mu \mathrm{g} \mathrm{C}]^{-1} \mathrm{~h}^{-1}\right)$, and $Z_{\mathrm{z}}$ is the copepod concentration in incubation bottles $(\mu \mathrm{g} C)$. 
An illustration of model compartments, trophic relations and model parameters is given in Fig. 1a. Growth rates for the micro- and nanoplankton derived from the analysis of control incubations (Eqs. 7 to 10) were used in Eqs. (11) to (14) to derive copepod grazing rates in the treatments with added copepods. We assumed a conversion efficiency of $50 \%$ for the microzooplankton ( $f=0.5$ ). This model configuration and the resulting estimates are referred as the standard simulation (Table 2).
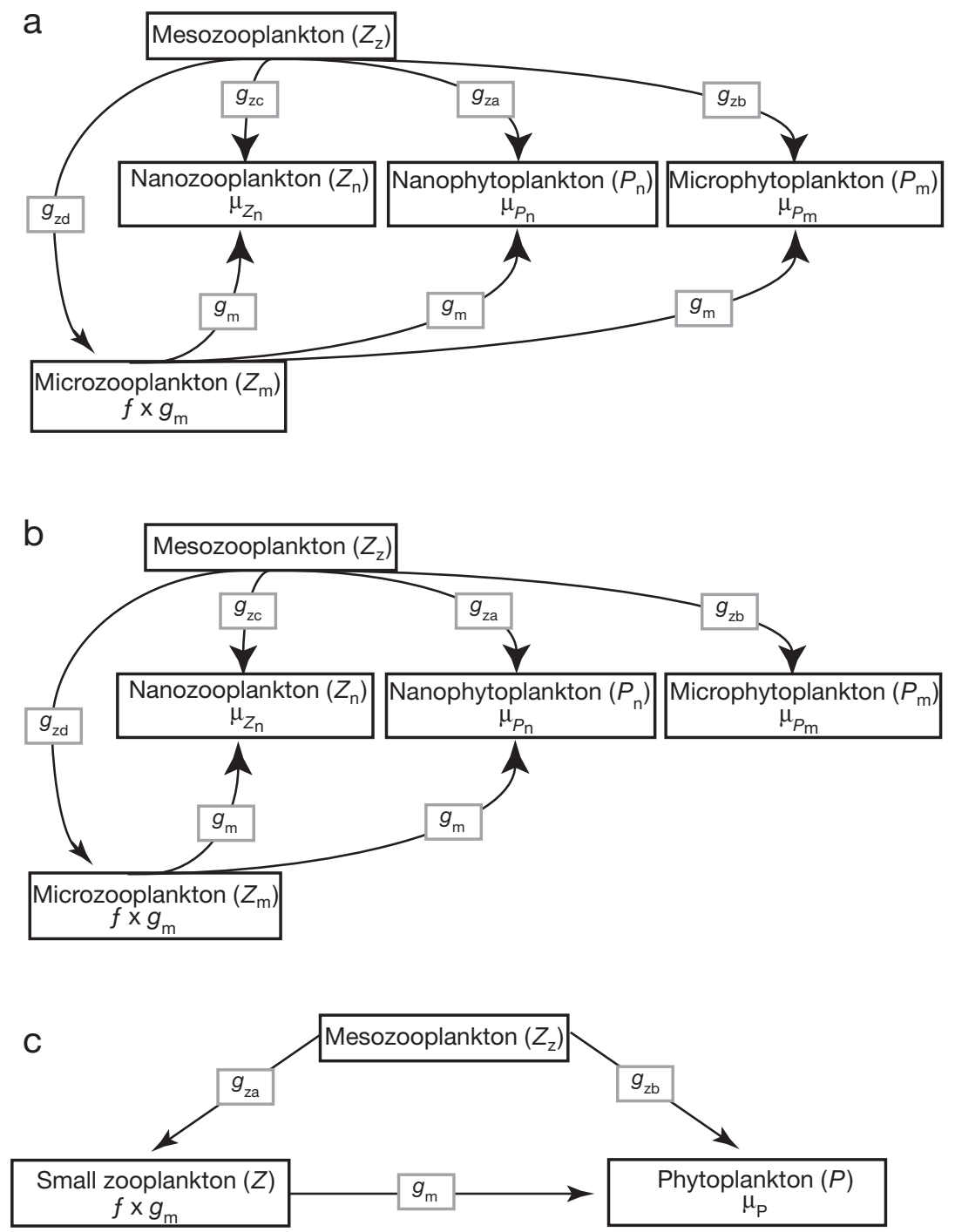

Fig. 1. General structure and parameters (italics) of the ecosystem models. Trophic relationships are indicated by arrows leading from predators to their prey. See 'Materials and methods' for explanation of parameters. (a) Standard model configuration for simulations type 1 and type 2. (b) Model configuration used in simulation type 3 (no microzooplankton grazing on microphytoplankton). (c) Model configuration used in simulation type 4 with 3 compartments only, viz. small zooplankton (nano- and microzooplanton), phytoplankton (nanoand microphytoplankton) and mesozooplankton (added copepods)
An initial approximation of model parameters was estimated by solving Eqs. (7) to (10) and then (11) to (14) using discrete differences between standing stocks of the planktonic groups at the beginning and the errors between plankton concentrations estimated using our model and measured values for all plankton groups were well below measurement uncertainties.

The sensitivity of copepod grazing estimates to model assumptions was also tested, particularly: (1) changes in conversion efficiency for microzooplankton (Fig. 1a, Table 2, simulation type 2); (2) changes in feeding selectivity of microzooplankton by assuming that microzooplankton feeds only on nanoplankton (Fig. 1b, Table 2, simulation type 3); (3) changes in model architecture using only one phytoplankton compartment comprising the nano- and microphytoplankton and one small zooplankton compartment comprising the nano- and microzooplankton (Fig. 1c, Table 2, simulation type 4). For the sensitivity analysis, model estimates of copepod grazing were calculated for one experiment with small copepods (Expt 7a), Calanus simillimus (Expt 2) and Rhincalanus gigas (Expt 6), respectively.

\section{RESULTS}

Initial and final standing stocks of nanophytoplankton, microphytoplankton, nanozooplankton and microzooplankton in the control treatments and copepod treatments are presented in Fig. 2. Uncorrected and corrected (standard simulation) grazing estimates are given in Table 3. Parameter value estimates for the standard simulation are given in Table 4 . Considering a carbon content of $2.82 \mu \mathrm{g} \mathrm{C}$ ind. ${ }^{-1}$ for small copepods, $44.8 \mu \mathrm{g} \mathrm{C}$ ind. ${ }^{-1}$ for Calanus simillimus CVI females, and $248.1 \mu \mathrm{g} \mathrm{C}$ ind.$^{-1}$ for Rhincalanus gigas CVI females (Schultes 2004), daily rations of metazooplankton grazers ranged from 0.15 to $5.5 \%$ of body car- 
Table 2. Model configurations and simulations carried out. Sim.: Simulation type. Simulation type 1 was run using the standard model configuration with a conversion efficiency of 0.5 for the microzooplankton and was referred to as the standard simulation. Simulation type 2 used the standard model configuration and a conversion efficiency of 0.3 for the microzooplankton. Simulation type 3 assumed that the microzooplankton grazed only on nanoplankton. Simulation type 4 assumed only 2 compartments in control incubations, viz. phytoplankton (nano- and microphytoplankton) and small zooplankton (nano- and micro zooplankton). $f$ : conversion efficiency

\section{Sim. Parameter and model configuration}

Type 15 compartments, no selectivity, $f=0.5 \quad$ (Fig. 1a)

Type 25 compartments, no selectivity, $f=0.3 \quad$ (Fig. 1a)

Type 35 compartments, selectivity, $f=0.5 \quad$ (Fig. 1b)

Type 43 compartments, no selectivity, $f=0.5 \quad$ (Fig. 1c) bon (\% BC) for uncorrected grazing rates and from 0.18 to $7.0 \%$ BC for corrected values (Table 3).

Without taking into account trophic interactions, several grazing estimates had negative signs, indicating that the addition of copepods had a positive feedback on growth of various categories of smaller organisms compared to the control incubations (Table 3). This was particularly the case in treatments with added Rhincalanus gigas. Values with a negative sign (i.e. positive feedback on prey organism) were not added into our estimates of total daily grazing rates per copepod given in Table 3. Corrected estimates using the ecosystem model to take into account trophic interactions were 18 to $30 \%$ higher than uncorrected estimates (Table 3). Model estimates of grazing parameters for the different copepod species on different food

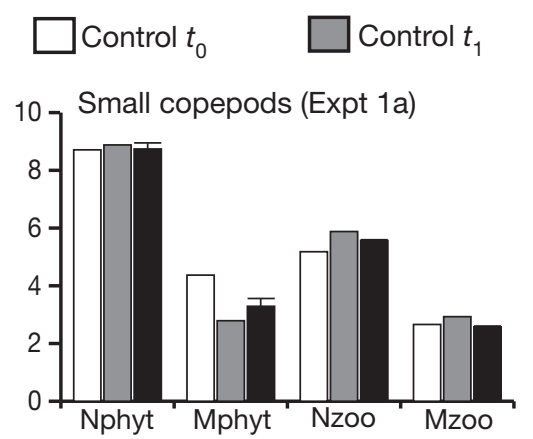

Copepod treatment $t_{1}$
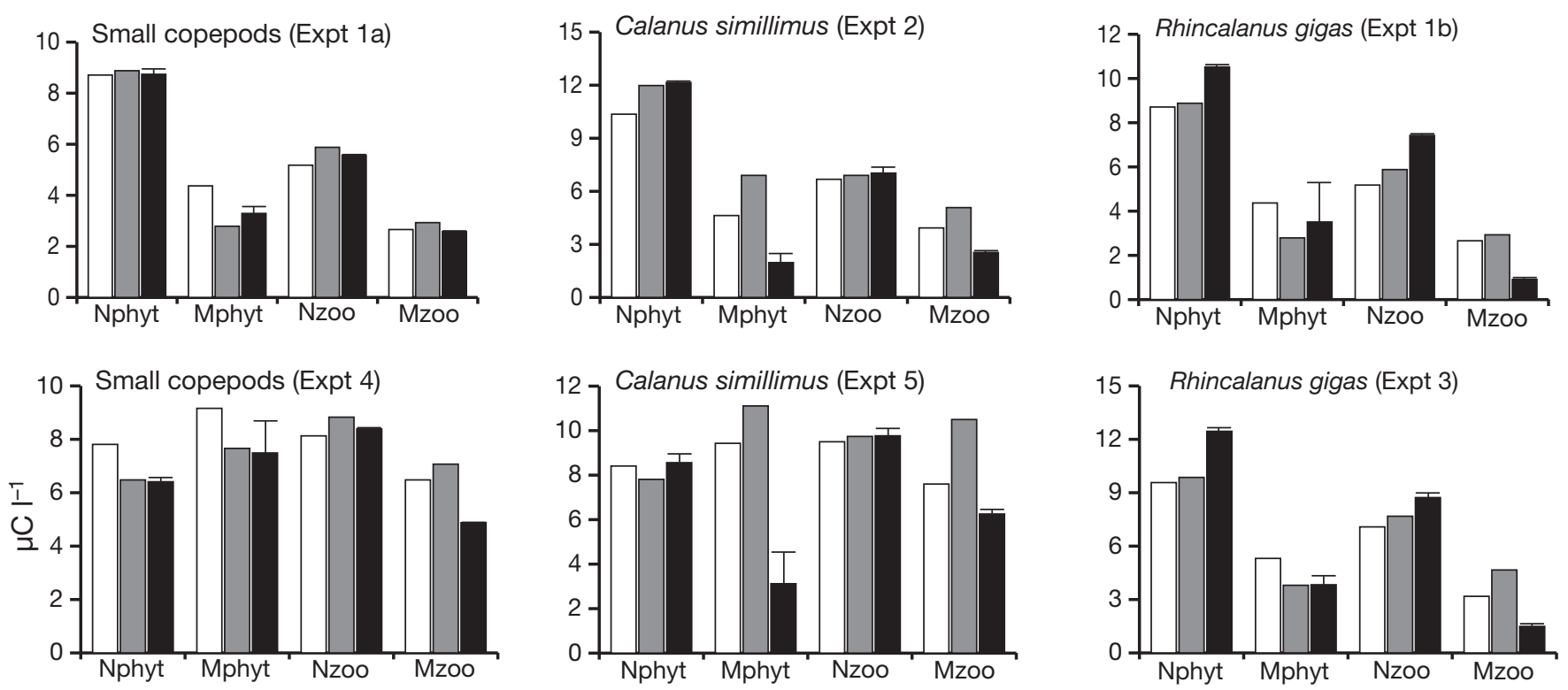

Small copepods (Expt 7a)
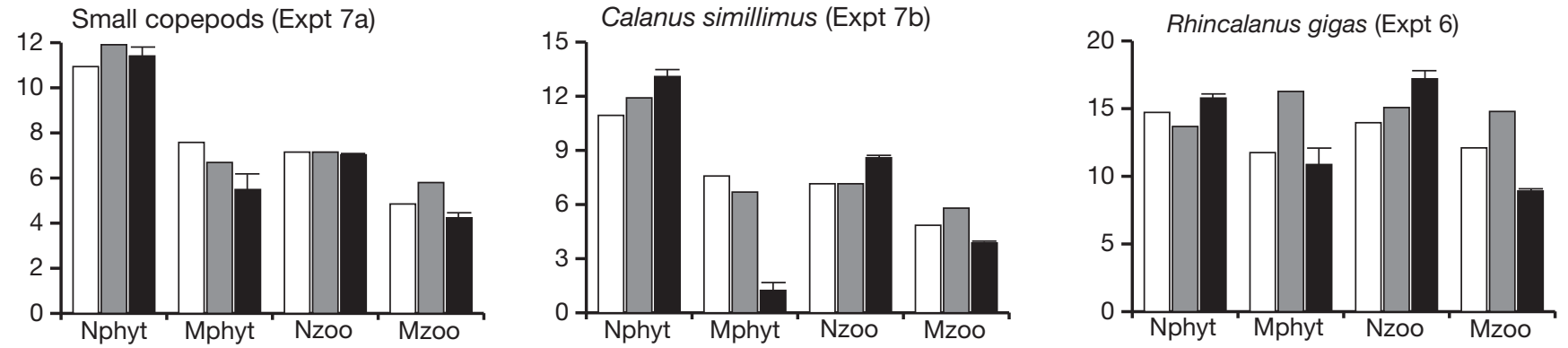

Fig. 2. Initial (Control $t_{0}$ ) and final plankton concentrations in incubation bottles with and without added copepods (Control $t_{1}$ and copepod treatment $t_{1}$, respectively) for the 6 incubation experiments used in this study. Species or size category of copepods added in copepod treatment and experiment number are given for each experiment. Values are given in $\mu \mathrm{g} C \mathrm{l}^{-1}$ for the nanophytoplankton (Nphyt), microphytoplankton (Mphyt), nanozooplankton (Nzoo) and microzooplankton (Mzoo). Error bars for final values for the copepod treatments represent $1 \mathrm{SD}$ of concentrations determined by microscopy counts of 3 replicate incubations 
Table 3. Copepod grazing on different compartments of the plankton during incubation experiments (uncorrected) and after taking into account trophic cascade effects (corrected). Expt: experiment number. Treatment: type of copepod added in grazing treatments: small copepods (Small cop.), Calanus simillimus (C. simil.) and Rhincalanus gigas (R. gigas). N: number of copepod individuals in treaments. Total grazing by added copepods on nanophytoplankton (Nphyt), microphytoplankton (Mphyt), nanozooplankton (Nzoo) and microzooplankton (Mzoo) for the duration of the incubation. Tot. C: individual copepod total daily carbon ingestion (for the uncorrected estimates of Tot. C, negative grazing values were excluded from calculation). Ing. C: individual copepod daily carbon ingestion in \% body carbon (\% BC)

\begin{tabular}{|c|c|c|c|c|c|c|c|c|c|c|c|c|c|c|}
\hline \multirow{2}{*}{ Expt } & \multirow{2}{*}{ Treatment } & \multirow{2}{*}{$\mathrm{N}$} & \multicolumn{6}{|c|}{ - Uncorrected } & \multirow{2}{*}{$\begin{array}{l}\text { Nphyt } \\
(\mu g \mathrm{C})\end{array}$} & \multirow[b]{2}{*}{$\begin{array}{l}\text { Mphyt } \\
(\mu g \text { C) }\end{array}$} & \multicolumn{2}{|c|}{ - Corrected } & \multirow[b]{2}{*}{$\begin{array}{c}\text { Tot. C } \\
\left(\mu g \mathrm{C} \mathrm{d}^{-1}\right. \\
\left.\text { ind. }^{-1}\right)\end{array}$} & \multirow[b]{2}{*}{$\begin{array}{l}\text { Ing. C } \\
(\% \text { BC })\end{array}$} \\
\hline & & & $\begin{array}{l}\text { Nphyt } \\
(\mu g \mathrm{C})\end{array}$ & $\begin{array}{l}\text { Mphyt } \\
(\mu g \mathrm{C})\end{array}$ & $\begin{array}{l}\text { Nzoo } \\
(\mu g \text { C) }\end{array}$ & $\begin{array}{l}\text { Mzoo } \\
(\mu g \text { C) }\end{array}$ & $\begin{array}{c}\text { Tot.C } \\
\left(\mu g \mathrm{C} \mathrm{d}^{-1}\right. \\
\left.\text { ind }^{-1}\right)\end{array}$ & $\begin{array}{l}\text { Ing. C } \\
(\% \text { BC) }\end{array}$ & & & $\begin{array}{l}\text { Nzoo } \\
(\mu g \mathrm{C})\end{array}$ & $\begin{array}{l}\text { Mzoo } \\
(\mu g \mathrm{C})\end{array}$ & & \\
\hline $1 \mathrm{a}$ & Small cop. & 10 & 0.14 & -0.62 & 0.29 & 0.34 & 0.08 & 2.7 & 0.19 & 0.00 & 0.36 & 0.40 & 0.10 & 3.5 \\
\hline 4 & Small cop. & 20 & 0.08 & 0.18 & 0.43 & 2.09 & 0.08 & 2.9 & 0.16 & 0.30 & 0.59 & 2.49 & 0.10 & 3.7 \\
\hline $7 a$ & Small cop. & 15 & 0.48 & 1.28 & 0.12 & 1.42 & 0.16 & 5.5 & 0.71 & 1.61 & 0.24 & 1.66 & 0.20 & 7.0 \\
\hline 2 & C. simil. & 5 & -0.16 & 3.90 & -0.13 & 2.21 & 1.05 & 2.3 & 0.18 & 4.74 & 0.07 & 2.53 & 1.29 & 2.9 \\
\hline 5 & C. simil. & 5 & -0.78 & 7.25 & -0.03 & 3.58 & 1.44 & 3.2 & 0.00 & 8.92 & 0.49 & 3.86 & 1.77 & 3.9 \\
\hline $7 \mathrm{~b}$ & C. simi. & 5 & -1.13 & 5.90 & -1.44 & 1.76 & 1.08 & 2.4 & 0.00 & 7.06 & 0.00 & 1.97 & 1.29 & 2.8 \\
\hline $1 \mathrm{~b}$ & R. gigas & 5 & -1.62 & -0.90 & -1.45 & 1.90 & 0.38 & 0.15 & 0.00 & 0.00 & 0.00 & 2.86 & 0.45 & 0.18 \\
\hline 3 & R. gigas & 4 & -2.55 & -0.04 & -1.01 & 2.54 & 0.35 & 0.14 & 0.00 & 0.27 & 0.00 & 3.04 & 0.46 & 0.19 \\
\hline 6 & R. gigas & 4 & -2.18 & 4.56 & -2.04 & 5.28 & 1.97 & 0.79 & 0.00 & 5.79 & 0.00 & 6.15 & 2.39 & 0.96 \\
\hline
\end{tabular}

types $\left(g_{\mathrm{za}}, g_{\mathrm{zb}}, g_{\mathrm{zc}}\right.$ and $g_{\mathrm{zd}}$, Table 4$)$ also illustrate selective feeding patterns, with higher small copepod grazing rates on microzooplankton followed by nanoplankton, higher Calanus simillimus grazing rates on microphytoplankton, and higher $R$. gigas grazing rates on microzooplankton. Furthermore, a shift in food selection was observed for all copepods, with a relative increase in grazing of diatoms in the last experiments. The interpretation of selectivity patterns based on uncorrected estimates by Schultes et al. (2006) is supported by our corrected grazing estimates.

Growth rates of nanophyto- and nanozooplankton estimated using the standard model and microscopy counts from control treatments seemed, however, too low to explain the development of the nanoplankton in some experiments with added Calanus simillimus, and more so for experiments with Rhincalanus gigas (Table 4), even though copepod grazing rates on the nanoplankton were set to zero in model simulations. Final nanoplankton abundances obtained using the model were lower by 7 to $20 \%$ than values found in experiments with added copepods. These differences are larger than the variability of nanoplankton counts (3\%) determined from triplicate treatments with added copepods.

The sensitivity of copepod grazing estimates to changes in conversion efficiency for microzooplankton, feeding selectivity of microzooplankton and model architecture is given in Table 5. A change of conversion efficiency from 50 to $30 \%$ led to only a slight increase in the final copepod grazing estimate and higher estimates of nanoplankton consumption for the small copepods and Calanus simillimus (Table 5, simulation types 1 and 2). However, no significant shift in grazing preference was found. Conversion efficiencies for microzooplankton had, therefore, only a minor effect on final estimation of copepod grazing rates. Copepod grazing estimates, assuming microzooplankton feeding only on nanoplankton (simulation type 3), did not differ significantly from grazing estimates assuming feeding of microzooplankton on nanoplankton and microphytoplankton (Table 5). Model-data differences in nanophytoplankton and nanozooplankton final standing stocks were reduced by only $1 \%$ in experiments with added Rhincalanus gigas. Results obtained using fewer ecological compartments (Fig. 1c, simulation type 4) were similar to values obtained with other simulations in experiments with small copepods and $C$. simillimus, but led to significantly lower grazing estimates in experiments with $R$. gigas.

\section{DISCUSSION}

Copepod grazing rates and feeding preferences derived from model simulations based on different assumptions were not sensitive to food selectivity and conversion efficiency (gross growth efficiency) of the microprotozoa, provided they were truly the top predators in the control treatments. Different conversion efficiencies for microprotozoa led to higher grazing rates by microprotozoa on nanoplankton and microphytoplankton. Higher microprotozoan grazing rates have to be compensated for by an increase in nanoplankton and microphytoplankton growth rates under the constraints of the data from the control experiments. Such changes, however, only marginally 


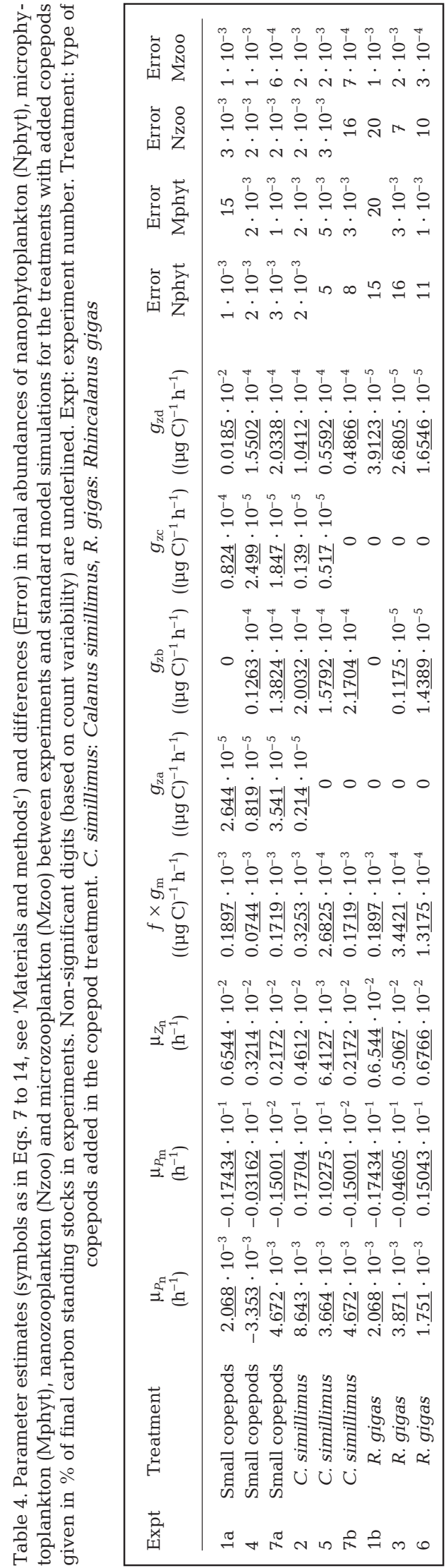

affected copepod grazing estimates and selectivity patterns. The same applies for changing the feeding preferences of microprotozoa. Furthermore, results were also insensitive to changes in number of model compartments, with the exception of experiments using Rhincalanus gigas due to the positive feedback of copepods on the growth of nanophytoplankton and nanozooplankton. The model was unable to solve for parameters simulating the nanoplankton increase in incubations with $R$. gigas compared to the control incubations, suggesting that, at least for nanoplankton, growth rates derived from the control incubations might have been underestimated. This could be due to the fact that grazing rates of microprotozoa on nanozooplankton and nanophytoplankton for the control treatments were underestimated (leading to an underestimate in the growth rates of their food). Model estimates (Table 3 ) were obtained assuming $f=0.5 \%$ for the microprotozoa. Although conversion efficiencies for zooplankton vary between a few percent and over $80 \%$, a value of $50 \%$ may be somewhat high (Straile 1997). We tested the influence of conversion efficiencies by using a value of $30 \%$. A change of conversion efficiency from 50 to $30 \%$ did not lead to significant improvement of model-data differences in Expt 6 with $R$. gigas (model-data difference decreased from 11 to $9 \%$ and from 10 to $8 \%$ for the nanophytoplankton and nanozooplankton final standing stocks, respectively). In addition, copepod grazing rate estimates were very similar for the 2 simulations.

A primary purpose of the experiments was to determine copepod feeding selectivity on the major phytoplankton and protozoan groups (diatoms, ciliates and heterotrophic dinoflagellates) during EisenEx (Schultes et al. 2006). Although several autotrophic flagellate species (including dinoflagellates) are likely to be mixotrophic, our current knowledge of ciliate and flagellate ecology is insufficient to determine which species are mixotrophic. Autotrophic flagellates were, therefore, considered as autotrophs and not counted. Conversely, since all ciliates are either heterotrophs or mixotrophs but probably never obligate autotrophs, all ciliates were considered as heterotrophs and were included in the microzooplankton counts. The presence of mixotrophic flagellates (including dinoflagellates) in the sample (not accounted for in the microprotozoan counts) is an additional factor that could lead to underestimation of microzooplankton grazing rates. A larger population of microprotozoan grazers due to the inclusion of mixotrophic flagellates in our model had, however, little effect on the results. To test this effect, a simulation assuming a doubling in the microzooplankton standing stocks compared to the standard run in Expt 6 was carried out (data not shown). This led to a doubling of nanoplankton growth rate estimates in 
Table 5. Estimates of copepod grazing rates on different compartments of the plankton during incubations using different growth efficiencies for the microzooplankton and different model configurations. Expt: experiment number, as in Table 1. Sim.: simulation type (see Table 2). Total grazing by added copepods on nanophytoplankton (Nphyt), microphytoplankton (Mphyt), all phytoplankton (Phyt), nanozooplankton (Nzoo), microzooplankton (Mzoo) and all small zooplankton (Zoo) for the total duration of the incubation. Tot. C: individual copepod total daily carbon ingestion

\begin{tabular}{|c|c|c|c|c|c|c|c|c|}
\hline Expt & Sim. & $\begin{array}{l}\text { Nphyt } \\
(\mu g \text { C) }\end{array}$ & $\begin{array}{l}\text { Mphyt } \\
(\mu g \text { C) }\end{array}$ & $\begin{array}{l}\text { Phyt } \\
(\mu g \mathrm{C})\end{array}$ & $\begin{array}{l}\text { Nzoo } \\
(\mu g \mathrm{C})\end{array}$ & $\begin{array}{l}\text { Mzoo } \\
(\mu g \mathrm{C})\end{array}$ & $\begin{array}{l}\text { Zoo } \\
(\mu \mathrm{g} \mathrm{C})(\mu \mathrm{g}\end{array}$ & 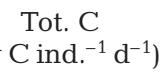 \\
\hline $7 a$ & 1 & 0.71 & 1.61 & 2.32 & 0.24 & 1.66 & 1.90 & 0.20 \\
\hline $7 \mathrm{a}$ & 2 & 0.80 & 1.66 & 2.47 & 0.30 & 1.66 & 1.96 & 0.21 \\
\hline $7 a$ & 3 & 0.77 & 1.53 & 2.29 & 0.27 & 1.68 & 1.95 & 0.20 \\
\hline $7 \mathrm{a}$ & 4 & - & - & 2.16 & - & - & 1.88 & 0.19 \\
\hline 2 & 1 & 0.18 & 4.74 & 4.92 & 0.07 & 2.53 & 2.77 & 1.29 \\
\hline 2 & 2 & 0.42 & 4.80 & 5.22 & 0.22 & 2.52 & 2.74 & 1.37 \\
\hline 2 & 3 & 0.30 & 4.65 & 4.95 & 0.15 & 2.62 & 2.77 & 1.32 \\
\hline 2 & 4 & - & - & 5.32 & - & - & 2.49 & 1.34 \\
\hline 6 & 1 & 0 & 5.79 & 5.79 & 0 & 6.15 & 6.15 & 2.39 \\
\hline 6 & 2 & 0 & 6.02 & 6.02 & 0 & 6.16 & 6.16 & 2.44 \\
\hline 6 & 3 & 0 & 5.43 & 5.43 & 0 & 6.32 & 6.32 & 2.35 \\
\hline 6 & 4 & - & - & 4.24 & - & - & 3.92 & 1.63 \\
\hline
\end{tabular}

the control treatments. However, this effect was counteracted by the correspondingly higher microzooplankton grazing effect on nanoplankton in the treatment with added Rhincalanus gigas, resulting in an underestimate of nanoplankton final standing stock similar to the standard model and the model assuming a microzooplankton conversion efficiency of $30 \%$.

Microzooplankton grazing rates and consequently nanoplankton growth rates in control incubations could also be underestimated if microprotozoa selectively fed on nanoplankton. This hypothesis was also tested by assuming that microprotozoa feed exclusively on nanoplankton (simulation type 3). Modeldata differences for nanophytoplankton and nanozooplankton final standing stocks were reduced only by $1 \%$ in Expt 6 with added Rhincalanus gigas. Hence, the high growth rates of nanoplankton (in particular in experiments with added $R$. gigas) indicate positive feedbacks that cannot be explained by a trophic cascade effect due to grazing by $R$. gigas (and possibly Calanus simillimus) on microprotozoa.

Finally, a combination of all previously discussed effects as well as counting errors could explain the development of nanoplankton in treatments with Rhincalanus gigas. This combination was tested for $R$. gigas (using results from Expt 6, Table 1) by maximizing nanoplankton and microzooplankton growth rate estimates based on the variability observed in count data for the triplicate copepod treatments (i.e. assuming 3 and $4 \%$ lower initial nanoplankton and microzooplankton standing stocks, respectively, and 3 and $4 \%$ higher nanoplankton and microzooplankton final standing stocks, respectively, in the control incuba- tions). In addition, microzooplankton was set to graze only on the nanoplankton, and $R$. gigas grazing effect in the copepod treatment was maximized by assuming lower than average final nanoplankton and microzooplankton stocks (by 3 and $4 \%$, respectively) for the treatment with added $R$. gigas. In order to reproduce nanoplankton evolution in this simulation, $R$. gigas grazing rates on the nanoplankton were still set to zero and final nanoplankton concentrations were still lower by 1 to $2 \%$ compared to count values. The additional assumption of a conversion efficiency of $30 \%$ (instead of $50 \%$ ) matched experimental data well and predicted some grazing by $R$. gigas on the nanoplankton. Estimates of $R$. gigas grazing for the experiment were $0.5 \mu \mathrm{gC}$ for nanophytoplankton, $3.9 \mu \mathrm{g} C$ for microphytoplankton, $0.7 \mu \mathrm{g}$ C for nanozooplankton and $7 \mu \mathrm{g}$ $\mathrm{C}$ for microzooplankton, resulting in a grazing rate of $2.42 \mu \mathrm{g} \mathrm{C}$ ind. ${ }^{-1} \mathrm{~d}^{-1}$. Hence, only the most favourable combination of counting errors, microzooplankton selectivity and a low conversion efficiency could explain nanoplankton dynamics in experiments using $R$. gigas. Although this combination of factors cannot be excluded, it seems unlikely that it occurred in a systematic manner during the experiments, whereas a strong positive feedback was only found in incubations with large copepods, and systematically in incubations with added $R$. gigas. Thus, other feedbacks or processes might have been involved.

One additional feedback might be an increase in nutrient availability and dissolved organic carbon (DOC) released by the feeding activity of the copepods leading to an increase in nanophytoplankton growth rates through enhanced nutrient supply, or indirectly through an increase in bacterial growth rates as a food source for the nanoplankton. Bacterial carbon concentrations during EisenEx were in the order of 3 to $8 \mu \mathrm{g} \mathrm{C}$ $\mathrm{l}^{-1}$, with production rates of 0.2 to $0.9 \mu \mathrm{g} \mathrm{C} \mathrm{d}^{-1}$ (Arrieta et al. 2004, Olivier et al. 2004). The nanoplankton biomass increases in treatments with Rhincalanus gigas (ca. $4 \mu \mathrm{g} \mathrm{C} \mathrm{l}^{-1}$ ) would correspond (assuming $50 \%$ conversion efficiency) to an increase in nanoplankton comsumption amounting to at least all of the bacterial biomass available and 10 times the bacterial production, assuming no grazing of the microzooplankton on the nanoplankton. Given the slow bacterial growth rates under the temperature conditions in the field and incubations (corresponding to a doubling every 3 to $5 \mathrm{~d})$ and the relatively short incubation times, an 


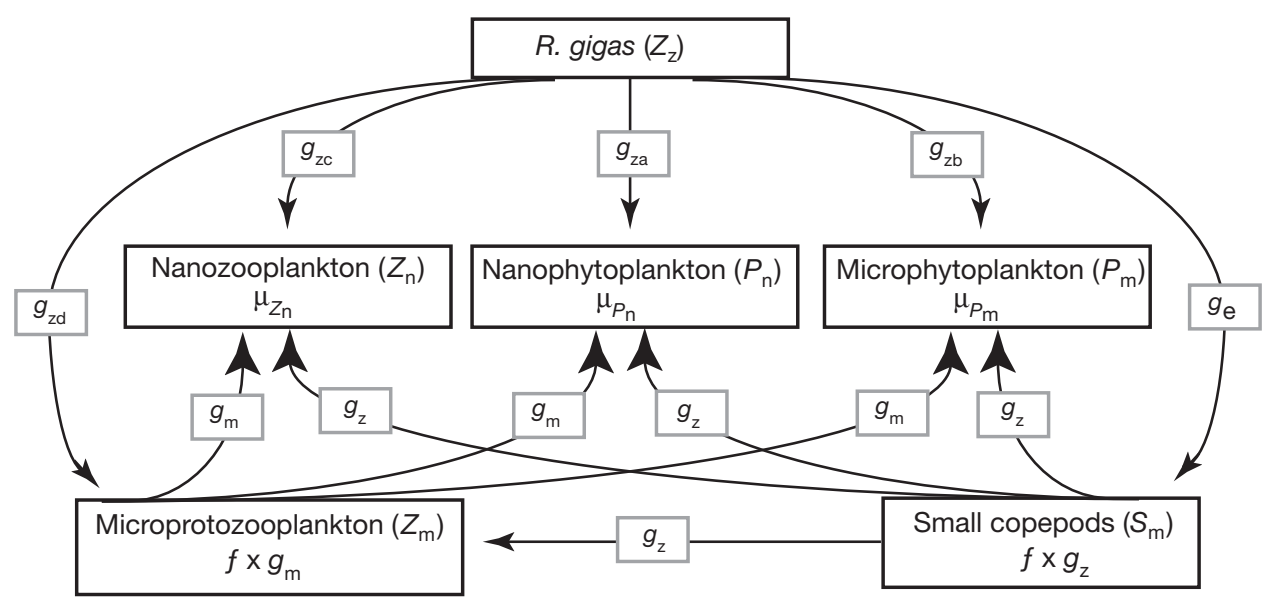

Fig. 3. Ecosystem model configuration and parameters used to estimate the effect of an additional trophic link composed of small copepods, copepodite and naupliar stages (small copepods box in the diagram) in Expt 6 with Rhincalanus gigas. Small copepods were assumed to graze unselectively with a specific grazing rate $\left(g_{\mathrm{z}}\right)$ and similar conversion efficiency $(f)$ as the rest of the microzooplankton and were grazed by $R$. gigas at rate $g_{\mathrm{e}}$ (grazing rates of added $R$. gigas on other small copepods present in both the control and copepod treatment bottles). Other parameters are the same as in the standard configuration (see 'Materials and methods' for definition of parameters)

increase in bacterial production and biomass required to explain the response of the nanoplankton in incubation bottles with $R$. gigas is, therefore, highly unlikely. Furthermore, experiments with $R$. gigas showed much larger positive feedback despite overall lower consumption levels in the incubation bottles compared to Calanus simillimus. Experiments were carried out in the dark, ruling out the possibility of an increase in growth rates of nanophytoplankton (due to increased nutrient supply) in the copepod treatments compared to control treatments. The positive feedback found upon addition of $R$. gigas, and possibly in incubations with $C$. simillimus, could also be due to additional trophic interactions. Evaluation of the experimental data and model did not consider the effect of grazers other than the microprotozoa in the control and copepod treatments. Copepod larval stages and small copepods (Oithona spp. and Ctenocalanus spp.) were abundant in the area of study (Henjes et al. 2007) and, given their relatively small sizes, were not removed from the community before incubation. It is, therefore, likely that additional grazing of nanoplankton and microplankton by small copepods occurred in all experiments (Atkinson 1994, 1996). We propose that $R$. gigas, in particular, can have a positive effect on phytoplankton growth by feeding both on microprotozoa and on smaller copepods. Feeding preferences of $R$. gigas are poorly known, but analysis of faecal pellet contents suggests that $R$. gigas also feeds on other metazoans (Arashkevich 1978, Pasternak 1995, Michels \& Schnack-Schiel 2005).

The presence of an additional trophic link (small copepods feeding on nano- and microplankton) implies that growth rates based on control incubations (and considering only microprotozoan grazing) might be underestimated. Consequently, grazing estimates for copepods might also be too low.

The effect of adding a trophic link was estimated in the model by assuming a small copepod component in the control and added copepod treatment (Fig. 3) in Expt 6 with Rhincalanus gigas (Table 1). Initial small copepod concentration in incubation bottles was assumed to be $7.5 \mu \mathrm{g} \mathrm{C}$, based on the values found during EisenEx by Henjes et al. (2007) and assuming that copepod naupliar stages do not graze. Grazing rates of small copepods on nano- and microplankton were set to 0.07 and 0.7 (ng C) ${ }^{-1} \mathrm{~h}^{-1}$, respectively, based on grazing parameters found in previous simulations (Table 4). Conversion efficiency for the small copepods was set to $50 \%$. Two estimates were made assuming no grazing of added copepods on small copepods already present in the community (Fig. 3, Table 6, $g_{\mathrm{e}}=$ 0 ), or assuming a grazing rate of added copepods of $g_{\mathrm{e}}=0.02(\mathrm{ng} \mathrm{C})^{-1} \mathrm{~h}^{-1}$ on the small copepods already present in the community (Fig. 3, Table 6, $g_{\mathrm{e}}=0.02$ ). This value is also within the range of grazing rate estimates given in Table 4. Estimated grazing rates for $R$. gigas on the different compartments and for the different parameters are given in Table 6. Best fit to the data was found by assuming high grazing rates for small copepods $\left(0.7[\mathrm{ng} \mathrm{C}]^{-1} \mathrm{~h}^{-1}\right)$ and significant grazing rates of $R$. gigas on the small copepods. In this simulation, small copepod grazing rates were higher than values found in experiments where small copepods were added (Expts 1a, 4 and 7a, Table 4). Also, assuming a conversion efficiency of $50 \%$, this would lead to a 
Table 6. Estimates of copepod grazing rates on different compartments of the plankton assuming an additional trophic link composed of small copepods calculated using results from Expt 6 with Rhincalanus gigas. Results from 4 simulations are presented assuming grazing rates by small copepods $\left(g_{\mathrm{z}}\right)$ on nano- and microplankton of 0.07 or $0.7(\mathrm{ng} \mathrm{C})^{-1} \mathrm{~h}^{-1}$, respectively, and assuming no grazing of added $R$. gigas on small copepods $\left(g_{\mathrm{e}}=0\right)$ or a grazing rate of $0.02(\mathrm{ng} \mathrm{C})^{-1} \mathrm{~h}^{-1}$. For comparison, the estimate based on the standard simulation without considering potential grazing impact by small copepods is also given. Simulation: model and parameter description. Total grazing from added $R$. gigas on nanophytoplankton (Nphyt), microphytoplankton (Mphyt), nanozooplankton (Nzoo), microzooplankton (Mzoo) and small copepods (Scop) for the whole duration of the incubation. C Ing.: daily carbon ingestion rates for individual $R$. gigas excluding the ingestion of small copepods. Tot. C: individual daily $R$. gigas carbon ingestion including feeding on small copepods. Values in brackets indicate model-data differences in \% of final standing stocks for the corresponding plankton compartments and simulations

\begin{tabular}{|c|c|c|c|c|c|c|c|}
\hline Simulation & $\begin{array}{l}\text { Nphyt } \\
\text { (ug C) }\end{array}$ & $\begin{array}{l}\text { Mphyt } \\
(\mu g \mathrm{C})\end{array}$ & $\begin{array}{l}\text { Nzoo } \\
(\mu g \mathrm{C})\end{array}$ & $\begin{array}{l}\text { Mzoo } \\
(\mu g \mathrm{C})\end{array}$ & $\begin{array}{l}\text { Scop } \\
(\mu \mathrm{g} \mathrm{C})\end{array}$ & $\begin{array}{c}\text { C Ing. } \\
\left(\mu \mathrm{g} \mathrm{C} \text { ind. } .^{-1} \mathrm{~d}^{-1}\right)\end{array}$ & $\begin{array}{c}\text { Tot. C } \\
\left(\mu \mathrm{g} \mathrm{C} \text { ind } .^{-1} \mathrm{~d}^{-1}\right)\end{array}$ \\
\hline Standard & $\begin{array}{c}0 \\
(11)\end{array}$ & $\begin{array}{c}5.79 \\
(0.001)\end{array}$ & $\begin{array}{c}0 \\
(10)\end{array}$ & $\begin{array}{c}6.15 \\
(0.003)\end{array}$ & - & 2.39 & 2.39 \\
\hline$g_{\mathrm{z}}=0.07 \& g_{\mathrm{e}}=0$ & $\begin{array}{c}0 \\
(11)\end{array}$ & $\begin{array}{c}5.82 \\
(0.0005)\end{array}$ & $\begin{array}{c}0 \\
(10)\end{array}$ & $\begin{array}{c}6.14 \\
(0.001)\end{array}$ & 0 & 2.39 & 2.39 \\
\hline$g_{\mathrm{z}}=0.07 \& g_{\mathrm{e}}=0.02$ & $\begin{array}{c}0 \\
(10)\end{array}$ & $\begin{array}{c}5.87 \\
(0.0002)\end{array}$ & $\begin{array}{c}0 \\
(9)\end{array}$ & $\begin{array}{c}6.19 \\
(0.0004)\end{array}$ & 3.48 & 2.41 & 3.11 \\
\hline$g_{\mathrm{z}}=0.7 \& g_{\mathrm{e}}=0$ & $\begin{array}{c}0 \\
(8)\end{array}$ & $\begin{array}{c}6.34 \\
(0.0006)\end{array}$ & $\begin{array}{c}0 \\
(7)\end{array}$ & $\begin{array}{c}6.16 \\
(0.0006)\end{array}$ & - & 2.50 & 2.50 \\
\hline$g_{\mathrm{z}}=0.7 \& g_{\mathrm{e}}=0.02$ & $\begin{array}{c}0 \\
(1.5)\end{array}$ & $\begin{array}{c}7.11 \\
(0.0001)\end{array}$ & $\begin{array}{c}0 \\
(0.4)\end{array}$ & $\begin{array}{c}6.9 \\
(0.0001)\end{array}$ & 4.63 & 2.80 & 3.73 \\
\hline
\end{tabular}

doubling of small copepod biomass within the control incubation. This seems excessive and one might speculate that several assumptions may be tenuous: (1) only half of the small copepods found during EisenEx were assumed to feed at any given time; this might have been an underestimation as some naupliar stages also feed; with a larger population of feeding copepods, grazing rates can be reduced in order to improve fit to the data; (2) the small copepods used in Expts 1a, 4 and $7 \mathrm{a}$ were hand picked and corresponded to the larger size range within the copepod community smaller than $2 \mathrm{~mm}$; it is, therefore, likely that an important fraction of the small copepods (naupliar and copepodite stages) has higher metabolic rates than those of the small copepods added in Expts $1 \mathrm{a}$, 4, and $7 \mathrm{a}$; (3) feeding preferences were assumed to be unimportant, but naupliar and copepodite stages could feed preferentially on nanoplankton given their small sizes; this is supported by the fact that a positive feedback upon addition of $R$. gigas was observed only for the nanoplankton; finally, (4) factors discussed previously (feeding preferences in the microzooplankton, conversion efficiency and counting errors) also affect the outcome of our simulations.

The presence of an additional trophic link leads to higher estimates of Rhincalanus gigas grazing rates. Estimates of ingestion increased by up to $56 \%$ in simulations where added $R$. gigas was assumed to feed on the small copepods compared to values obtained with the standard simulation (Table 6). These differences were, however, primarily due to the additional contribution of small copepods to final grazing estimates.
Grazing rates on nanoplankton, microphytoplankton and microprotozoa increased by at most $17 \%$ compared to standard estimates. In addition, no significant differences in feeding selectivity by $R$. gigas were found, although, in order to improve fit of the data, growth rates had to be increased by a factor of 2 for the microplankton and up to a factor of 8 for the nanophytoplankton.

The results obtained using different ecosystem model configurations and assumptions imply that the model provides robust estimates of copepod grazing and selectivity as constrained by microscopy counts of nanoand microplankton, even with the exclusion of data on small copepods in control and copepod treatments. One exception to these conclusions are Rhincalanus gigas grazing estimates using the model configuration with microplankton and nanoplankton pooled into one group (Fig. 1c, Table 5, simulation type 4). The positive feedback of $R$. gigas on nanozooplankton and nanophytoplankton leads (when these groups are pooled with the corresponding microplankton groups) to a significant underestimate of copepod grazing on phytoplankton and zooplankton. These results indicate that grazing estimates are generally not sensitive to the number of model compartments (experiments with small copepods and Calanus simillimus) as long as no positive feedbacks occur on species or groups within the compartments considered. In cases where positive feedback occurs on species or groups, model compartments should be specified accordingly. Furthermore, information on abundance, feeding and growth rates of the smallest copepods and copepod developmental 
stages (in particular nauplii and copepodites) could help to constrain the grazing by and on smaller metazoa that cannot be separated from the protists in incubation experiments using natural communities.

\section{CONCLUSIONS}

Grazing rates and grazing selectivity of Southern Ocean copepods were determined using incubation experiments comparing the plankton community evolution with and without added grazers and different ecosystem model configurations in order to correct for trophic cascade effects. Sensitivity of copepod grazing estimates to different model configurations and parameter values using a 5-compartment model (nanophytoplankton, nanozooplankton, microphytoplankton, microzooplankton and the added copepods) or a 3compartment model (protozooplankton, phytoplankton and the added copepods) was tested. The resulting copepod grazing rates were generally insensitive to model configuration and parameters (number of compartments, grazing selectivity and changes in gross growth efficiency of the microzooplankton) with the exception of experiments with the large copepod Rhincalanus gigas. The addition of $R$. gigas had a significant positive feedback on the nanophytoplankton and nanozooplankton, and grazing estimates were lower when these groups were not resolved by the model compartments. Hence, model aggregation level should discriminate between species or groups where positive feedbacks occur and those where no positive feedback is observed. Furthermore, our model simulations of experiments with added $R$. gigas suggest the presence of an additional trophic link, probably constituted of small copepods and copepod larval stages. These results support previous observations indicating that $R$. gigas does feed on other small crustaceans. Consequently, total copepod grazing rates might be underestimated in experiments where copepodite and naupliar stages are not considered. The presence of an additional trophic link does not, however, have a large influence on estimates of copepod grazing on the nanoplankton, microphytoplankton and microprozoa. Hence, the combination of incubation experiments with ecosystem models provides a useful tool for determining copepod grazing rates and investigating trophic relationships and selectivity in the plankton.

Acknowledgements. We thank the captain and crew of RV 'Polarstern' for their helpful assistance during leg ANTXVIII/2, D. Wolf-Gladrow and J. Nejstgaard for valuable discussions and careful reading of this manuscript. P.G.V. was supported by USA National Science Foundation grants OPP00-83381 and OCE-05-45312. S.S. was supported by Marie Curie Intra European Fellowship No. 010882 'ZOOPALIS'.

\section{LITERATURE CITED}

Arashkevich E (1978) Some characteristics of the copepod feeding. Tr Inst Okeanol 112:118-125

Arrieta JM, Weinbauer MG, Lute C, Herndl GJ (2004) Response of bacterioplankton to iron fertilization in the Southern Ocean. Limnol Oceanogr 49:799-808

Atkinson A (1994) Diets and feeding selectivity among the epipelagic copepod community near South Georgia in summer. Polar Biol 14:551-560

Atkinson A (1996) Subantarctic copepods in an oceanic, low chlorophyll environment: ciliate predation, food selectivity and impact on prey populations. Mar Ecol Prog Ser 130: 85-96

Baars MA, Helling GR (1985) Methodological problems in the measurement of phytoplankton ingestion rate by gut fluorescence. Hydrobiol Bull 19:81-88

Cisewsky B, Strass VH, Prandke H (2005) Upper-ocean vertical mixing in the Antarctic Polar Front Zone. Deep-Sea Res I 52:1087-1108

Conover RJ, Durvasula R, Roy S, Wang R (1986) Probable loss of chlorophyll-derived pigments during passage through the gut of zooplankton, and some of the consequences. Limnol Oceanogr 31:878-887

Gervais F, Riebesell U, Gorbunov MY (2002) Changes in primary productivity and chlorophll $a$ in response to iron fertilization in the Southern Polar Frontal Zone. Limnol Oceanogr 47:1324-1335

Head EJH, Harris LR (1992) Chlorophyll and carotenoid transformation and destruction by Calanus spp. grazing on diatoms. Mar Ecol Prog Ser 86:229-238

Henjes J, Assmy P, Klaas C, Smetacek V (2007) Response of microzooplankton (protists and small copepods) to an iron-induced bloom in the Southern Ocean (EisenEx). Deep-Sea Res I 54:363-384, doi: 10.1016/j.dsr.2006.12.004

Ikeda T (1977) The effect of laboratory conditions on the extrapolation of experimental measurements to the ecology of marine zooplankton. IV. Changes in respiration and excretion rates of boreal zooplankton species maintained under fed and starved conditions. Mar Biol 41:241-252

Ikeda T, Torres JJ, Hernández-León S, Geiger SP (2000) Metabolism. In: Harris R, Wiebe P, Lenz J, Skjoldal HR, Huntley M (eds) ICES zooplankton methodology manual. Academic Press, London, p 455-532

Landry MR, Hassett RP (1982) Estimating the grazing impact of marine micro-zooplankton. Mar Biol 67:283-288

Michels J, Schnack-Schiel SB (2005) Feeding in dominant Antarctic copepods-does the morphology of the mandibular gnathobase relate to diet? Mar Biol 146: 483-495

Nejstgaard JC, Gismervik I, Solberg PT (1997) Feeding and reproduction by Calanus finmarchicus, and microzooplankton grazing during mesocosm blooms of diatoms and the coccolithophore Emiliania huxleyi. Mar Ecol Prog Ser $147: 197-217$

Nejstgaard JC, Naustvoll LJ, Sazhin A (2001) Correcting for underestimation of microzooplankton grazing in bottle incubation experiments with mesozooplankton. Mar Ecol Prog Ser 221:59-75

Olivier JL, Barber RT, Smith WO, Ducklow HW (2004) The heterotrophic bacterial response during the Southern Ocean Iron Experiment (SOFEX). Limnol Oceanogr 49: $2129-2140$

Pasternak A (1995) Gut content and diel feeding rhythm in dominant copepods in the ice-covered Weddell Sea, March 1992. Polar Biol 15:583-586

Peterson W, Painting S, Barlow R (1990) Feeding rates of 
Calanoides carinatus: a comparison of five methods including evaluation of the gut fluorescence method. Mar Ecol Prog Ser 63:85-92

Roman MR, Rublee PA (1980) Containment effects in copepod grazing experiments: a plea to end the black box approach. Limnol Oceanogr 25:982-990

Schultes S (2004) The role of mesozoooplankton grazing in the biogeochemical cycle of silicon in the Southern Ocean. $\mathrm{PhD}$ thesis, Bremen University

Schultes S, Verity PG, Bathmann U (2006) Copepod grazing during an iron-induced diatom bloom in the Antarctic Circumpolar Current (EisenEx): I. Feeding patterns and grazing impact on prey populations. J Exp Mar Biol Ecol 338:16-34

Editorial responsibility: Otto Kinne, Oldendorf/Luhe, Germany
Smetacek V, Bathmann U, El Naggar S (2001) The expeditions ANTARKTIS XVIII/1-2 of the Research Vessel 'Polarstern' in 2000. Ber Polarforsch Meeresforsch 400: $1-134$

Straile D (1997) Gross growth efficiencies of protozoan and metazoan zooplankton and their dependence on food concentration, predator-prey weight ratio, and taxonomic group. Limnol Oceanogr 42:1375-1385

Utermöhl H (1958) Zur Vervollkommnung der quantitativen Phytoplankton-Methodik. Mitt Int Ver Theor Angew Limnol 9:1-38

Zeldis J (2001) Mesozooplankton community composition, feeding, and export production during SOIREE. Deep-Sea Res II 48:2615-2634

Submitted: March 1, 2007; Accepted: September 24, 2007 Proofs received from author(s): March 17, 2008 